\title{
Scaling-Up Catalytic Depolymerisation of Lignin: Performance Criteria for Industrial Operation
}

\author{
Panos D. Kouris ${ }^{1} \cdot$ Xiaoming Huang $^{1} \cdot$ Michael D. Boot $^{1,2} \cdot$ Emiel J. M. Hensen $^{1}$
}

Published online: 6 September 2018

(c) The Author(s) 2018

\begin{abstract}
Much scientific research has been carried to convert lignin into valuable biobased chemicals or fuels. Most of these studies had the objective to develop active and selective catalysts for effective lignin depolymerization; this with little regard for the parameters that are necessary for later commercialization of these technologies. In this work, we have chosen as a case study a process that has been extensively studied and reported on earlier by our group. This process converts (technical) lignin into mainly aromatic compounds, using supercritical ethanol and a $\mathrm{Cu}-\mathrm{Mg}-\mathrm{Al}$ mixed oxide catalyst. Here, we investigate the impact of scaling up this process from lab to bench scale. More specifically, we study the influence of higher lignin loadings than previously reported on, amongst other parameters, monomer yield, solvent losses and catalyst fouling; all of which being critical performance parameters for industrial operation. After we examined the technical feasibility of our process at $4 \mathrm{~L}$ scale, we further looked into the economic viability of this technology, by introducing two performance criteria, both of which being a function of lignin monomer yield. The ratios $(\mathrm{g} / \mathrm{g})$ of yield over total feed, and yield over ethanol losses are presented as qualitative indicators for capital expenditure (CAPEX) and operational expenditure (OPEX), respectively. This exercise sheds some much needed light on the trade-off between yield optimization and cost minimization.
\end{abstract}

Keywords Biomass $\cdot$ Lignin $\cdot$ Supercritical ethanol $\cdot$ Scaling up $\cdot$ Industrial operation

\section{Introduction}

Lignocellulosic biomass is the primary terrestrial source of renewable carbon. Conversion of lignocellulose to fuels and chemicals is therefore subject of widespread research. For nearly two millennia, cellulose alone has been processed towards higher value products. Historically, this has been paper pulp, but more recently cellulosic ethanol too has been building up momentum. In both cases, lignin, which comprises up to 19-35 wt\% of lignocellulosic biomass [1], has either been dumped in rivers [2] or burnt on-site for energy. Though a trending topic now at academia and industry alike,

Emiel J. M. Hensen

e.j.m.hensen@tue.nl

1 Schuit Institute of Catalysis, Inorganic Materials Chemistry, Eindhoven University of Technology, P.O. Box 513, 5600 MB Eindhoven, The Netherlands

2 Combustion Technology, Department of Mechanical Engineering, Eindhoven University of Technology, P.O. Box 513, 5600 MB Eindhoven, The Netherlands its valorization towards higher value products has largely been a side note throughout history.

Owing to its notorious chemical recalcitrance and structural complexity, processing of lignin has proven quite challenging indeed. The primary difficulty lies in selectively breaking down the main bonds between the basic chemical building blocks, required to defunctionalize the lignin and obtain the target products. Lignin is a natural amorphous three-dimensional polymer consisting of $p$-hydroxyphenyl $(\mathrm{H})$, guaiacyl $(\mathrm{G})$ and syringyl $(\mathrm{S})$ units cross-linked by $\mathrm{C}-\mathrm{O}-\mathrm{C}(\beta-\mathrm{O}-4, \alpha-\mathrm{O}-4,4-\mathrm{O}-5)$ and $\mathrm{C}-\mathrm{C}(\beta-1, \beta-\beta, 5-5)$ bonds [3]. Ether bonds are easier to cleave than $\mathrm{C}-\mathrm{C}$ bonds in particular due to the lower bond dissociation energy (BDE). The $\beta-\mathrm{O}-4$ ether bond is the most common bond in native lignin and has a BDE of $226-290 \mathrm{~kJ} / \mathrm{mol}$ relative to $524-532 \mathrm{~kJ} / \mathrm{mol}$ for a typical C-C bond [4].

The past decade has witnessed an exponential growth in scientific research concerning the catalytic conversion of lignin to fuels and base chemicals [1,5]. Lignin depolymerization into smaller, aromatic molecules, often requires solvents, catalysts, and hydrogen for deoxygenation. Solvents including methanol [6-8] ethanol [3, 9-11] ethanol/water 
$[12,13]$ methanol/water [14] propanol [15] or dioxane [16, 17] have been investigated in detail as a medium for tandem solvolysis and hydrogenolysis reactions. These latter reactions can be catalyzed both by transition ( $\mathrm{Pt}, \mathrm{Pd}, \mathrm{Ru}, \mathrm{Rh}$, etc.) and more abundant metals $(\mathrm{Cu}, \mathrm{Ni}$, etc.). Importantly, for effective bond cleavage and high yields of aromatic compounds, relatively severe conditions are typically applied.

In most of the aforementioned literature, the lignin-tosolvent ratios going into the reactor were chosen between $1: 30$ and $1: 60 \mathrm{w} / \mathrm{v}$, with higher lignin loadings generally manifesting in prohibitively high char formation and/or low conversion towards mono-aromatics [3, 6, 7, 9-12]. Here, we refer to our early work as a case in point, wherein we demonstrated an effective approach for lignin depolymerization to mono-aromatics in supercritical ethanol, using a $\mathrm{Cu}-\mathrm{Mg}-\mathrm{Al}$ mixed oxide catalyst [3,9-11]. In this work, a high solvent to lignin ratio was used with the aim to obtain a high yield of lignin monomers. The main rationale for such diluted ratios is to prevent fouling of the equipment and catalyst surface. Such fouling is caused by deposition of heavy insoluble materials that are either present in the feedstock or formed in situ by decomposition or repolymerization reactions [18]. While interesting from a scientific stance, such diluted feeds would require an unrealistically high capital expenditure (CAPEX), given that CAPEX scales quite well with total volume/mass flow through the plant. Moreover, were such ratios to be applied commercially, even seemingly insignificant solvent losses of a mere few percents at lab scale, arising from, for example, flashing or chemical conversion towards less useful compounds [19], would surely be considered unacceptably high.

Based on our earlier work on lignin depolymerization, we move a big step forward by not only scaling it up from a 100 to $4000 \mathrm{~mL}$ batch reactor, but also by addressing aforementioned trade-off between conversion and selectivity to monomers (i.e., lignin oil value drivers) and practical issues concerning high solvent dilution (i.e., lignin oil cost drivers). Process scale-up, by definition, will generate important knowledge needed to transfer ideas into successful implementations [20]. Scaling up step by step and following a stage gate process, ensures that the technological risk with large investments could be lessened [21]. Such insights, which have hitherto been largely overlooked in the scientific literature, will help us scale up the process once more, now to a $250 \mathrm{~L}$ batch reactor, which is scheduled for commission by late 2018 .

The objective of this work is twofold. First, the technical feasibility of the earlier lab-scale $(100 \mathrm{~mL})$ recipe is assessed by a series of both repeat and further optimization experiments at the bench scale $(4000 \mathrm{~mL})$. Second, the economic viability of the technology is evaluated with the aid of two performance criteria, both of which being a function of lignin monomer yield. To this end, for relative operational expenditure (OPEX), we calculated the ratio $(\mathrm{g} / \mathrm{g})$ of said yield over solvent losses, defined here as conversion of ethanol to an arguably less valuable mixture of higher alcohols (e.g., produced via concurrent Guerbet chemistry [10]). Relative CAPEX, assumed here to scale with total mass flow running through the plant, is assessed by computing the ratio $(\mathrm{g} / \mathrm{g})$ between lignin monomer yield and total mass flow [22, 23]. At this work, we do not perform detailed economic analysis on CAPEX and OPEX, but a sensitivity analysis using specific integrated indicators based on the process parameters that influence them. Table 1 summarizes the most important performance criteria for commercial operation of technologies on lignin conversion where a heterogeneous catalyst and a solvent are involved.

Table 1 Performance criteria for industrial operation of lignin depolymerization technologies and their importance

\begin{tabular}{|c|c|c|}
\hline Criteria & Parameter & Comments \\
\hline Effect of scale & Geometric similarity & $\begin{array}{l}\text { Two processes may be considered completely similar and } \\
\text { compared accordingly, only if they take place in the same } \\
\text { geometrical space and if all the dimensionless geometric } \\
\text { ratios have the same numerical value [24] }\end{array}$ \\
\hline Lignin: solvent ratio (CAPEX driver) & Ratio $(\mathrm{g} / \mathrm{g})$ of monomers/feed & $\begin{array}{l}\text { Combination of undiluted feed and high selectivity to prod- } \\
\text { ucts are preferred; this ratio should be relatively high to } \\
\text { ensure affordable CAPEX for commercialization }\end{array}$ \\
\hline Solvent losses (OPEX driver) & Ratio $(\mathrm{g} / \mathrm{g})$ of monomers/solvent losses & $\begin{array}{l}\text { Excessive use of solvent or solvent losses in the process are } \\
\text { unfavorable and may be considered as the basic lignin oil } \\
\text { cost drivers }\end{array}$ \\
\hline Catalyst fouling (CAPEX/OPEX driver) & Ratio (g/g) of monomers/catalyst loading & $\begin{array}{l}\text { Deposition of heavy and poorly soluble lignin fragments } \\
\text { onto catalyst surface drops the catalyst activity; additional } \\
\text { CAPEX required for catalyst regeneration; new concepts } \\
\text { to avoid contact of the fouling agents with the catalyst are } \\
\text { needed }\end{array}$ \\
\hline
\end{tabular}




\section{Experimental Section}

\subsection{Chemicals and Materials}

Protobind 1000 alkali lignin was purchased from GreenValue, which is produced by means of soda pulping of wheat straw. This particular lignin is void of sulphur and contains only minor amounts of impurities (e.g., $<4 \mathrm{wt} \%$ carbohydrates and $<2 \mathrm{wt} \%$ ash). All commercial chemicals were analytical reagents and were used without further purification.

\subsection{Catalyst Preparation}

$20 \mathrm{wt} \% \mathrm{Cu}$-containing $\mathrm{MgAl}$ mixed oxide $\left(\mathrm{CuMgAlO}_{\mathrm{x}}\right)$ catalyst was prepared by a co-precipitation method with a fixed $\mathrm{M}^{2+} / \mathrm{M}^{3+}$ atomic ratio of $4 . \mathrm{CuMgAlO}_{\mathrm{x}}(100 \mathrm{~g})$ was prepared in the following way: $50.87 \mathrm{~g}$ of $\mathrm{Na}_{2} \mathrm{CO}_{3}$ was solved in $300 \mathrm{~mL}$ of deionized water and filled into a $2 \mathrm{~L}$ beaker, then warmed to $60^{\circ} \mathrm{C} .500 \mathrm{~mL}$ of $50 \mathrm{wt} \% \mathrm{NaOH}$ solution was subsequently poured into a $500 \mathrm{~mL}$ dropping funnel. In parallel, $70.71 \mathrm{~g}$ $\mathrm{Cu}\left(\mathrm{NO}_{3}\right)_{2} \cdot 2.5 \mathrm{H}_{2} \mathrm{O}, 332.30 \mathrm{~g} \mathrm{Mg}\left(\mathrm{NO}_{3}\right)_{2} \cdot 6 \mathrm{H}_{2} \mathrm{O}$, and $150.05 \mathrm{~g}$ $\mathrm{Al}\left(\mathrm{NO}_{3}\right)_{3} \cdot 9 \mathrm{H}_{2} \mathrm{O}$ were dissolved in $500 \mathrm{~mL}$ deionized water and poured into a $500 \mathrm{~mL}$ dropping funnel. Aforementioned 2 solutions were then slowly added to the $300 \mathrm{~mL} \mathrm{Na}_{2} \mathrm{CO}_{3}$ solution, while stirring and keeping the $\mathrm{pH}$ of the slurry at 10. Next, the precipitate was filtered and washed until the filtrate reached a pH of 7 . The solid was then dried overnight at $105^{\circ} \mathrm{C}$ and later grinded until fine powder like particles were obtained. Finally, the powder was calcined at $460{ }^{\circ} \mathrm{C}$ for $6 \mathrm{~h}$ in static air. The resulting catalyst was denoted by $\mathrm{Cu}_{20} \mathrm{MgAl}(4)$.

\subsection{Catalytic Activity Measurements}

A $4000 \mathrm{~mL}$ Parker stirred high-pressure autoclave was used to study the catalytic conversion of lignin in ethanol. Typically, the autoclave was charged with a suspension of catalyst in the range 20-80 $\mathrm{g}$ and lignin in the range of 40-160 $\mathrm{g}$ in $1600 \mathrm{~mL}$ solvent. An amount of $400 \mu \mathrm{L} n$-dodecane was added as the internal standard. The reactor was sealed and purged with nitrogen several times to remove oxygen. After leak testing, the pressure was set to $10 \mathrm{bar}$, and the reaction was heated to the desired reaction temperature under continuous stirring at 500-850 rpm. Once the reaction was finished, the heater was turned off and the reactor was left to cool down overnight, until a temperature below $35{ }^{\circ} \mathrm{C}$ was obtained.

\subsection{Lignin Product Analysis}

The liquid phase product mixture was analysed by a Shimadzu 2010 GC-MS system equipped with an RTX-1701 column $(60 \mathrm{~m} \times 0.25 \mathrm{~mm} \times 0.25 \mu \mathrm{m})$ and a flame ionization detector (FID), together with a mass spectrometer detector. Identification of products was achieved based on a search of the MS spectra with the NIST11 and NIST11s MS libraries. These products were further divided into four groups, namely hydrogenated cyclics (-o (oxygen-free)), hydrogenated cyclics ( + o (oxygen-containing)), aromatics $(-0)$ and aromatics $(+o)$, according to the nature of the ring structure and functional groups. All the quantitative analyses of liquid phase products were based on 1D GCFID. Experimentally determined weight response factors of cyclohexane, cyclohexanone, ethyl benzene and ethyl guaiacol were used for these four groups related to $n$-dodecane as the internal standard. Finally, the yields were calculated by using Eqs. $(1,2,3)$.

Mass $(\mathrm{mg})=\frac{\text { Area }_{\mathrm{i}}}{\text { Area }_{\text {Dodecane }} \times \text { Response factor }_{i}} \times$ Mass $_{\text {Dodecane }}$

Yield of lignin monomers (wt\%)

$$
\begin{aligned}
= & \frac{\text { weight of monomers (calculated from GC }- \text { FID) }}{\text { weight of starting soda lignin }} \\
& \times 100 \%
\end{aligned}
$$

EtOH conversion (wt $\%)$

$$
\begin{aligned}
= & \frac{\text { weight of EtOH in products (calculated from GC }- \text { FID) }}{\text { weight of starting EtOH }} \\
& \times 100 \%
\end{aligned}
$$

\subsection{Elemental Analysis (NCHS)}

Nitrogen, carbon, hydrogen, and sulphur (NCHS) content of the lignin residue was determined quantitatively by means of elemental analysis (PerkinElmer 2400 series II Elemental Analyser, NCHS mode). The lignin samples were dried overnight in a vacuum oven at $60{ }^{\circ} \mathrm{C}$, so as to remove residual water and solvent. Carbon and hydrogen analysis was conducted by combustion, followed by thermal conductivity and infrared detection of effluent gases. Finally, the oxygen content was determined by closing the mass balance under the assumption that the samples consisted solely of $\mathrm{C}, \mathrm{O}$, and $\mathrm{H}$ atoms.

\subsection{Catalyst Characterization}

N2 physisorption was measured on a Tristar 3000 system. The samples were then degassed at $300{ }^{\circ} \mathrm{C}$ for $5 \mathrm{~h}$ prior to measurements. The metal content of the fresh catalysts was subsequently determined by inductively coupled plasmaatomic emission spectrometry (ICP-AES) on a Spectro Ciros CCD ICP optical emission spectrometer, with axial plasma viewing. The resulting samples were dissolved in an equivolumetric mixture of $\mathrm{H}_{2} \mathrm{O}$ and $\mathrm{H}_{2} \mathrm{SO}_{4}$. Carbon deposition on the catalyst was investigated with Scanning Electron Microscopy with Energy Dispersive X-ray spectroscopy (SEM/ 
EDX). Samples were dissolved in acetone and deposited on a silicon wafer, and then dried. The specimen was then mounted on carbon tape affixed to an aluminium SEM stub, and imaged using a Phenom World ProX scanning electron microscope with an integrated energy dispersive spectrometer, equipped with a backscatter electron detector. Acceleration voltages of $10-15 \mathrm{kV}$ were used. Elemental analysis was performed using the Element Identification (EID) software package. Operational settings restricted detection to five elements: carbon, oxygen, magnesium, copper, and aluminium.

\section{Results and Discussion}

\subsection{Technological Feasibility}

The recommended approach for scaling up a catalytic process follows a similar stage gate process to that used in traditional Chemical Process Industry (CPI) processes [25]. Technology development benefits from stage gates at which the viability of the technology can be assessed before commercialization, in order to minimize the technological risk with larger investments [21, 26, 27]. Earlier, we have demonstrated a technology in our group, at lab scale, that is able to obtain predominantly mono-aromatics from technical lignin using a CuMgAl mixed oxide catalyst [3,9-11]. We evaluated the catalytic performance for soda lignin conversion in supercritical ethanol at lab scale in 50 and $100 \mathrm{~mL}$ autoclaves [11] and optimized the operating window towards a maximum yield of mono-aromatics. Monomer yields of $20 \mathrm{wt} \%$ and $30 \mathrm{wt} \%$ were obtained from conversion of P1000 soda lignin at $340{ }^{\circ} \mathrm{C}$ for $4 \mathrm{~h}$ over $\mathrm{Cu}_{20} \mathrm{MgAl}(4)$, at 50 and $100 \mathrm{~mL}$ scale, respectively. In this work, we move one step forward, and evaluate our technology at bench scale in a $4000 \mathrm{~mL}$ autoclave, prior to piloting in $250 \mathrm{~L}$ autoclave in late 2018.

Table 2 summarizes the results for soda lignin conversion in supercritical ethanol at bench scale. The lignin: ethanol feeding ratio was initially chosen as $1: 40 \mathrm{w} / \mathrm{v}$, in order to compare bench-scale performance with earlier lab-scale work in the $100 \mathrm{~mL}$ autoclave [11].

First, we studied the influence of reaction temperature on lignin monomer yield. To this end, the temperature was varied from 200 to $340{ }^{\circ} \mathrm{C}$, whereby the latter temperature was the maximum operational temperature allowed in the $4 \mathrm{~L}$ autoclave. Without catalyst, at $200{ }^{\circ} \mathrm{C}$ and $240{ }^{\circ} \mathrm{C}$, scarcely any lignin monomers could be obtained. In the presence of the $\mathrm{Cu}_{20} \mathrm{MgAl}(4)$ catalyst, as expected and based on our data from the lab scale, the monomers yield increases with reaction temperature (Table 2, entries 2-4). Even higher monomers yield could be achieved at longer reaction times (Table 2, entries 5-7). A monomer yield of $28 \mathrm{wt} \%$ was obtained when increasing reaction temperature and reaction time to $340{ }^{\circ} \mathrm{C}$ and $8 \mathrm{~h}$, respectively. Figure 1a shows a typical lignin-derived product distribution of the monomer fraction of the products obtained after reaction at $340{ }^{\circ} \mathrm{C}$ for $8 \mathrm{~h}$ over $\mathrm{Cu}_{20} \mathrm{MgAl}(4)$ for the $4 \mathrm{~L}$ autoclave. Comparing entry 4 with data from the small $100 \mathrm{~mL}$ autoclave (Table 2, entry 8 ), lignin selectivity to monomers decreased and their distribution differentiated, with less aromatic compounds being produced.

The most important observation during these experiments was that the monomer yield decreased by a factor 3 in the bench scale compared to the optimum case of the lab scale (Fig. 1b, c). Poor mixing behavior could be one of the reasons for the decreased yields. Depending on the

Table 2 Monomers yield and ethanol conversion following lignin depolymerization as a function of temperature, pressure, and reaction time, with and without a catalyst

\begin{tabular}{|c|c|c|c|c|c|c|c|c|c|c|}
\hline Entry & Catalyst & $\begin{array}{l}\text { Temp. } \\
\left({ }^{\circ} \mathrm{C}\right)\end{array}$ & $\begin{array}{l}\mathrm{P}_{\text {hot }} \\
\text { (bar) }\end{array}$ & $\begin{array}{l}\text { Lignin: } \\
\text { EtOH ratio } \\
(w / v)\end{array}$ & $\begin{array}{l}\text { Time } \\
\text { (h) }\end{array}$ & $\begin{array}{l}\text { Lignin } \\
\text { Monomers } \\
(\mathrm{wt} \%)\end{array}$ & $\begin{array}{l}\text { Ethanol } \\
\text { conversion } \\
(\mathrm{wt} \%)\end{array}$ & $\begin{array}{l}\text { Mass mono- } \\
\text { mers/Total } \\
\text { feed } \\
(\mathrm{g} / \mathrm{g}) \times 10^{-3}\end{array}$ & $\begin{array}{l}\text { Mass monomers/ } \\
\text { Ethanol losses } \\
(\mathrm{g} / \mathrm{g}) \times 10^{-3}\end{array}$ & $\begin{array}{l}\text { Mass monomers/ } \\
\text { Catalyst loading } \\
(\mathrm{g} / \mathrm{g})\end{array}$ \\
\hline \multicolumn{11}{|c|}{ Reactions in $4000-\mathrm{mL}$ autoclave $^{\mathrm{a}}$} \\
\hline $1 \mathrm{a}$ & Blank & 200 & 45 & $1: 40$ & 4 & 1 & 4 & 0.30 & 7.92 & - \\
\hline $1 b$ & Blank & 240 & 63 & $1: 40$ & 4 & 2 & 6 & 0.61 & 10.56 & - \\
\hline 2 & $\mathrm{Cu}_{20} \mathrm{MgAl}(4)$ & 240 & 67 & $1: 40$ & 4 & 1 & 12 & 0.30 & 2.64 & 0.02 \\
\hline 3 & $\mathrm{Cu}_{20} \mathrm{MgAl}(4)$ & 280 & 89 & $1: 40$ & 4 & 3 & 21 & 0.92 & 4.52 & 0.06 \\
\hline 4 & $\mathrm{Cu}_{20} \mathrm{MgAl}(4)$ & 340 & 185 & $1: 40$ & 4 & 11 & 49 & 3.37 & 7.11 & 0.22 \\
\hline 5 & $\mathrm{Cu}_{20} \mathrm{MgAl}(4)$ & 340 & 186 & $1: 40$ & 8 & 21 & 53 & 6.45 & 12.55 & 0.42 \\
\hline 6 & $\mathrm{Cu}_{20} \mathrm{MgAl}(4)$ & 340 & 184 & $1: 40$ & 8 & 26 & 55 & 7.98 & 14.98 & 0.52 \\
\hline 7 & $\mathrm{Cu}_{20} \mathrm{MgAl}(4)$ & 340 & 187 & $1: 40$ & 8 & 28 & 58 & 8.60 & 15.30 & 0.56 \\
\hline \multicolumn{11}{|c|}{ Reaction in $100-\mathrm{mL}$ autoclave ${ }^{\mathrm{b}}$} \\
\hline 8 & $\mathrm{Cu}_{20} \mathrm{MgAl}(4)$ & 340 & 168 & $1: 40$ & 4 & 30 & 31 & 9.21 & 30.67 & 0.6 \\
\hline
\end{tabular}

${ }^{\mathrm{a}} 4000 \mathrm{~mL}$ autoclave conditions: $40 \mathrm{~g}$ of lignin, $20 \mathrm{~g}$ of catalyst, $1600 \mathrm{~mL}$ of solvent and $500 \mathrm{rpm}$ stirring speed

${ }^{\mathrm{b}} 100 \mathrm{~mL}$ autoclave conditions [10]: $1 \mathrm{~g}$ of lignin, $0.5 \mathrm{~g}$ of catalyst, $40 \mathrm{~mL}$ of solvent and $500 \mathrm{rpm}$ stirring speed 

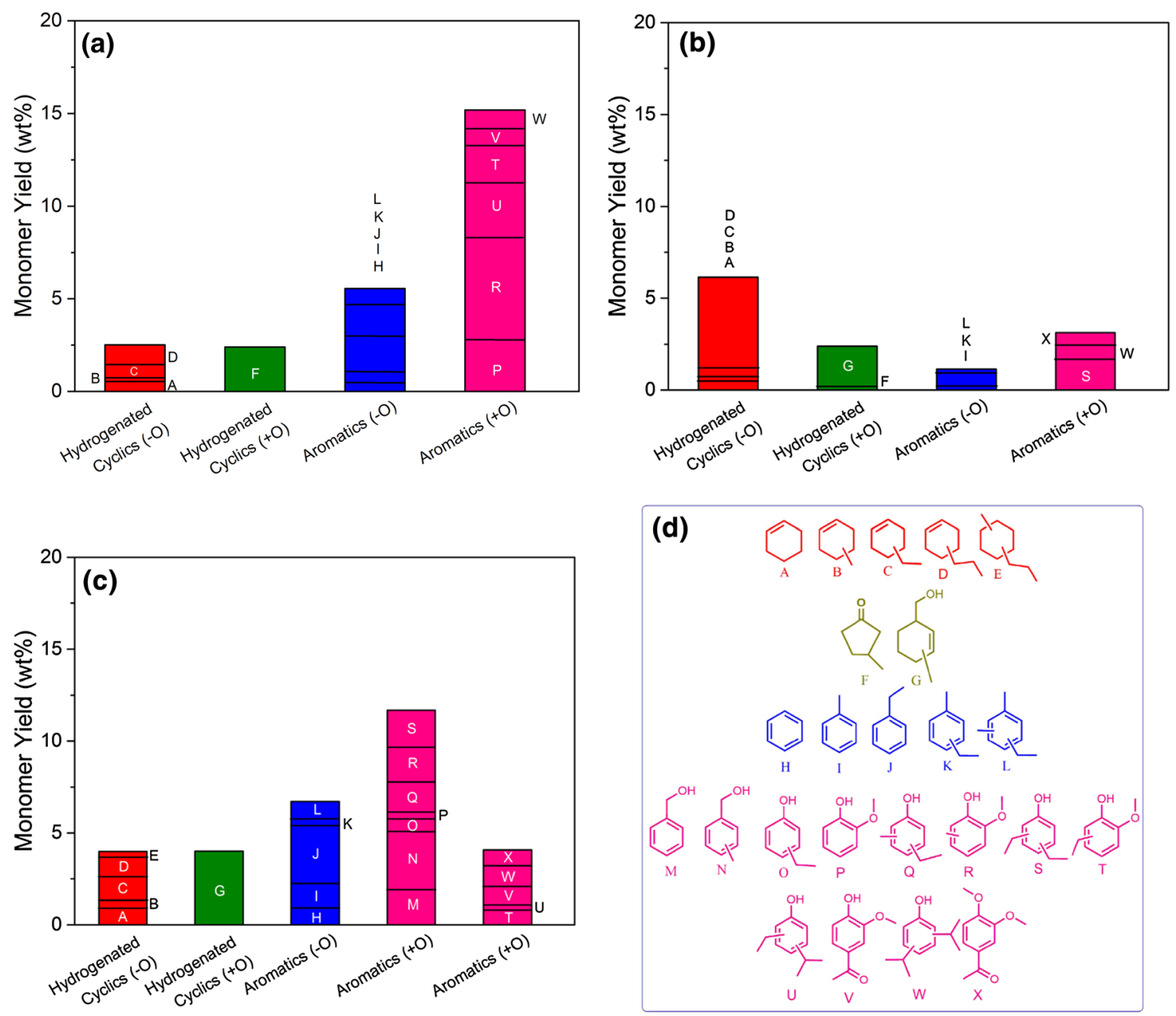

Fig. 1 a Lignin monomer yield distribution in $4 \mathrm{~L}$ bench scale (entry 6 , Table 2) at $340{ }^{\circ} \mathrm{C}$ and $8 \mathrm{~h}$ reaction time; b Lignin monomer yield distribution in $4 \mathrm{~L}$ bench scale (entry 4 , Table 2 ) at $340{ }^{\circ} \mathrm{C}$ and $4 \mathrm{~h}$ reaction time; c Lignin monomer yield distribution in $100 \mathrm{~mL}$ lab scale (entry 8, Table 2) at $340{ }^{\circ} \mathrm{C}$ and $4 \mathrm{~h}$ reaction time (obtained from Huang et al. [10] and modified after permission); d Main lignin monomer structures, involving different side-chain linkages

circulation pattern in the vessel, it is possible for relatively stagnant zones of lignin to develop. These zones are sometimes referred to as "dead zones". These zones can result from incorrectly sized impellers, inappropriate baffles, or incorrect tank geometry [28]. A production mixing unit of pilot scale is usually not geometrically similar to the unit used for process development in lab or bench scale. Such a difference can normally make scaling-up from the laboratory to pilot plant challenging. Geometric similarity is a term which is often used in these cases and practically means that a single ratio between small and large scale applies to every dimension of the reactor. All dimensions in the large scale equipment are set by the corresponding dimensions in the small scale unit. An equally important geometric scale-up parameter is the rotational speed [29]. Large scale rotational

and aromatic units, identified by MS spectra of the product mixtures obtained from the catalytic reactions of soda lignin at different conditions, using NIST11 and NIST11s libraries. The monomers were grouped in four categories: $[\mathrm{A}]-[\mathrm{E}]$ hydrogenated cyclic products without oxygen; $[\mathrm{F}]-[\mathrm{G}]$ hydrogenated cyclic products with oxygen; $[\mathrm{H}]-[\mathrm{L}]$ aromatic products without oxygen; $[\mathrm{M}]-[\mathrm{X}]$ aromatic products with oxygen

speed occurs when the small scale mixing speed is multiplied by the geometric ratio of the impeller diameters of both units. Figure 2 illustrates the geometric dissimilarities in our case between the $100 \mathrm{~mL}$ and $4 \mathrm{~L}$ autoclaves. Data on dimension (ratios) are presented in Table 3.

The calculated geometric ratios in Table 3, illustrate that there is an inconsistency in the geometry of the $4 \mathrm{~L}$ autoclave. To achieve the same reactor performance, tank sizing should follow geometric similarity. The two important tank characteristics of the $4 \mathrm{~L}$ reactor, whose incorrect dimensions are likely responsible for the observed poor mixing behavior, are the diameter of the pitch blade impeller and its distance from the bottom. To resolve these issues, mechanical and operational optimization is proposed. Hereby, four baffles were added and the operational stirring speed was 


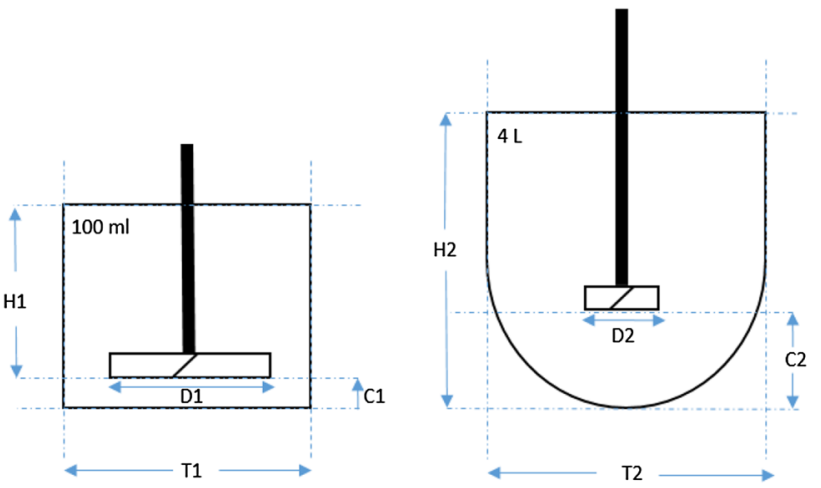

Fig. 2 Tank geometry for both lab and bench scale autoclaves (where $H$ height, $T$ tank diameter, $C$ distance of impeller from bottom, $D$ impeller diameter)

increased from 500 to $850 \mathrm{rpm}$. The latter speed was computed by simply multiplication of the lab scale stirring speed with the geometric ratio of the impellers.

\subsection{Economic Feasibility}

The importance of ethanol as a solvent in this process and its involvement in the lignin conversion reactions has been earlier also reported by our group $[3,9,10]$. Besides ethanol reforming into hydrogen, for the hydrogenolysis reactions, ethanol also reacts with lignin by aromatic ring alkylation and
Guerbet-type reactions with particular functional groups of lignin. Ethanol is also consumed by self-condensation reactions, thereby forming higher alcohols and esters, also via Guerbet chemistry. Ethanol reforming and conversion to higher alcohols is more pronounced at higher temperatures. Reaction at $340{ }^{\circ} \mathrm{C}$ for $8 \mathrm{~h}(28 \mathrm{wt} \%$ lignin monomers, entry 7 in Table 2$)$ results in ethanol consumption of about 58\%. The main reaction products derived from ethanol were $\mathrm{C} 3-\mathrm{C} 11$ alcohols and $\mathrm{C} 4-\mathrm{C} 10$ esters, along with small amounts of aldehydes, ketones, and hydrocarbons. In other words, a high value, high purity product is converted into an arguably less valuable, complex blend of numerous derivatives thereof, which have to been separated downstream to retrieve their value again.

In an attempt to lower solvent losses relative to lignin monomer yield, we varied the lignin: ethanol ratio $(w / v)$ from the original $1 \mathrm{~g}$ lignin: $40 \mathrm{~mL}$ ethanol ratio, to $1: 30$ $\mathrm{w} / \mathrm{v}, 1: 20 \mathrm{w} / \mathrm{v}$, and 1:10 w/v. The lignin-to-catalyst ratio remained constant at 2:1 w/w (Table 4). In this set of experiments, the stirring speed was increased from 500 to $850 \mathrm{rpm}$ in order to overcome the geometric disparities (Table 3) and enrich the mixing behaviour during the reaction.

Firstly, we observed that the total monomer yield increased from 11 to $12.8 \mathrm{wt} \%$ when stirring speed was optimized at $850 \mathrm{rpm}$. This slight improvement indicates the effect of poor mixing properties in the $4 \mathrm{~L}$ batch reactor and the presence of geometric dissimilarities with the lab scale reactors. With respect to higher lignin loading (Table 4 entry 3 ), monomer yield reached the value of $23 \mathrm{wt} \%$. Figure 3

Table 3 Dimensions (ratios) for lab and bench scale autoclaves

\begin{tabular}{lllll}
\hline & Tank diameter $(\mathrm{cm})$ & Height $(\mathrm{cm})$ & $\begin{array}{l}\text { Distance bot- } \\
\text { tom }(\mathrm{cm})\end{array}$ & Impeller diameter $(\mathrm{cm})$ \\
\hline 100 mL autoclave & $\mathrm{T}_{1}=4.5$ & $\mathrm{H}_{1}=8$ & $\mathrm{C}_{1}=1$ & $\mathrm{D}_{1}=3$ \\
4 L autoclave & $\mathrm{T}_{2}=12.5$ & $\mathrm{H}_{2}=35$ & $\mathrm{C}_{2}=5$ & $\mathrm{D}_{2}=5$ \\
Geometric ratio & $\mathrm{T}_{2} / \mathrm{T}_{1}=2.8$ & $\mathrm{H}_{2} / \mathrm{H}_{1}=4.4$ & $\mathrm{C}_{2} / \mathrm{C}_{1}=5$ & $\mathrm{D}_{2} / \mathrm{D}_{1}=1.7$ \\
\hline
\end{tabular}

Table 4 Monomer yield and ethanol conversion following lignin depolymerization as a function of lignin-to-ethanol ratio

\begin{tabular}{lllllllll}
\hline Entry & $\begin{array}{l}\text { Temp. } \\
\left({ }^{\circ} \mathrm{C}\right)\end{array}$ & $\begin{array}{l}\mathrm{P}_{\mathrm{hot}} \\
(\mathrm{bar})\end{array}$ & $\begin{array}{l}\text { Lignin: EtOH } \\
\text { ratio } \\
(\mathrm{w} / \mathrm{v})\end{array}$ & $\begin{array}{l}\text { Lignin mono- } \\
\text { mers } \\
(\mathrm{wt} \%)\end{array}$ & $\begin{array}{l}\text { Ethanol con- } \\
\text { version } \\
(\mathrm{wt} \%)\end{array}$ & $\begin{array}{l}\text { Mass monomers/ } \\
\text { total feed } \\
(\mathrm{g} / \mathrm{g}) \times 10^{-3}\end{array}$ & $\begin{array}{l}\text { Mass monomers/ } \\
\text { ethanol losses } \\
(\mathrm{g} / \mathrm{g}) \times 10^{-3}\end{array}$ & $\begin{array}{l}\text { Mass monomers/ } \\
\text { catalyst loading } \\
(\mathrm{g} / \mathrm{g})\end{array}$ \\
\hline 1 & 340 & 190 & $1: 40^{\mathrm{a}}$ & 12.8 & 47 & 3.93 & 8.62 & 0.25 \\
2 & 340 & 189 & $1: 30^{\mathrm{b}}$ & 15 & 46 & 6.04 & 13.60 & 0.29 \\
3 & 340 & 198 & $1: 20^{\mathrm{c}}$ & 23.1 & 47 & 13.77 & 31.10 & 0.46 \\
4 & 340 & 209 & $1: 10^{\mathrm{d}}$ & 9.2 & 36 & 10.35 & 32.40 & 0.18 \\
\hline
\end{tabular}

In all the cases the catalyst was $\mathrm{Cu}_{20} \mathrm{MgAl}(4)$ and the reaction time $4 \mathrm{~h}$

All experiments were performed at $850 \mathrm{rpm}$ stirring speed

a $4 \mathrm{~L}$ autoclave conditions: $40 \mathrm{~g}$ of lignin, $20 \mathrm{~g}$ of catalyst and $1600 \mathrm{~mL}$ of solvent

${ }^{\mathrm{b}} 4 \mathrm{~L}$ autoclave conditions: $53 \mathrm{~g}$ of lignin, $26 \mathrm{~g}$ of catalyst and $1600 \mathrm{~mL}$ of solvent

${ }^{\mathrm{c}} 4 \mathrm{~L}$ autoclave conditions: $80 \mathrm{~g}$ of lignin, $40 \mathrm{~g}$ of catalyst and $1600 \mathrm{~mL}$ of solvent

${ }^{\mathrm{d}} 4 \mathrm{~L}$ autoclave conditions: $160 \mathrm{~g}$ of lignin, $80 \mathrm{~g}$ of catalyst and $1600 \mathrm{~mL}$ of solvent 
shows the associated lignin monomer distribution obtained after a reaction at $340{ }^{\circ} \mathrm{C}$ for $4 \mathrm{~h}$ over $\mathrm{Cu}_{20} \mathrm{MgAl}(4)$.

The main products were aromatics with hydrogenated cyclic products as the main side-products. Most of these products were alkylated with methyl and/or ethyl groups substituted on the rings (Fig. 1d). Notably, by increasing the lignin loading by factor of 2 , the monomer yield also improved. The performance obtained at $340{ }^{\circ} \mathrm{C}$ for $1: 20$ w/v ratio, was better than the diluted case (Table 2, entry 4), likely because of the improved solubility of lignin in ethanol. Higher lignin loading, after mechanical optimization of the reactor and increased stirring speed, results in an improved mixing flow pattern in the $4 \mathrm{~L}$ reactor. The hot pressure reached in this case, was significantly higher, which is a consequence of the extensive reforming of ethanol into hydrogen-rich gaseous products during the reaction, due to the fact that a higher catalyst loading is being used. Higher hydrogen pressure facilitates hydrogenolysis reactions,

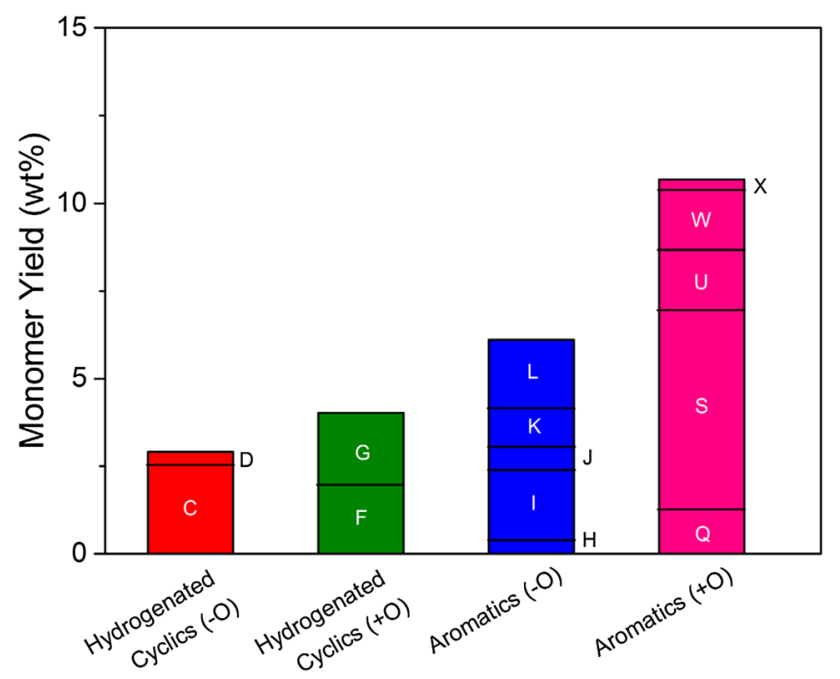

Fig. 3 Lignin monomer yield distribution in the $4 \mathrm{~L}$ autoclave (Table 4, entry 3 ) at $340{ }^{\circ} \mathrm{C}$ and $4 \mathrm{~h}$ reaction time which effectively improves the lignin monomer yield [11]. Further increasing the lignin loading to $1: 10 \mathrm{w} / \mathrm{v}$ resulted in a monomer yield of around $9 \mathrm{wt} \%$ (Table 4, entry 4). A possible explanation on this result is the limited solubility of lignin in ethanol at such high lignin loading. In our earlier work [11], in the optimum case of the lab scale experiments, where diluted feed (1:40 w/v lignin: ethanol ratio) was used, lignin showed excellent solubility in ethanol with little char formation (1 wt \%). So, the more lignin we introduce in the system, the lower solubility can we achieve. The reason why the selectivity to monomers drops so significantly in the last case (Table 4, entry 4), will be accordingly discussed later.

Following a work-up procedure on the reaction product mixture, that was developed earlier by our group [3], we determined the tetrahydrofuran (THF)-soluble and larger (THF-insoluble) lignin fragments (Table 5), for the different reactions on varying lignin: ethanol ratio. The results illustrate that both lignin depolymerization and repolymerization reactions are enhanced at $340{ }^{\circ} \mathrm{C}$. At high lignin: solvent ratio (Table 5 , entry 1 ), the solubility of lignin is expected to be high based on our experience from lab scale experiments, but the poor reactor geometry seems to promote the formation of THF-insoluble lignin fragments. This has, of course, a consequence on the low monomer yield that is being reported as the larger molecular weight lignin fragments are strongly adsorbed on the solid catalyst. Although higher lignin loadings (Table 5, entries 2-4), can overcome the issues of stagnant lignin zones resulting at an optimum monomer yield of $23 \mathrm{wt} \%$ (Table 5, entry 3), the lignin solubility barrier is responsible for the gradual increase of the THF-insoluble lignin compositions, which deactivate finally the catalyst.

Next to these, although we were able to replenish the monomer yield by applying higher lignin loadings (Table 4 , entry 3) and increase it from 11 to $23 \mathrm{wt} \%$, the lignin: ethanol ratio has still a profound impact on the defined CAPEX and OPEX indicators presented in Table 1. Comparing all the reactions at bench scale (Tables 2, 4), we observe that the
Table 5 Yields of monomers, lignin residues, and total yield for entries 1-4 of Table 4

\begin{tabular}{lllllll}
\hline Entry & $\begin{array}{l}\text { Temp. } \\
\left({ }^{\circ} \mathrm{C}\right)\end{array}$ & $\begin{array}{l}\text { Lignin: EtOH } \\
\text { ratio } \\
(\mathrm{w} / \mathrm{v})\end{array}$ & $\begin{array}{l}\text { Lignin } \\
\text { monomers } \\
(\mathrm{wt} \%)\end{array}$ & $\begin{array}{l}\text { Yield THF-solu- } \\
\text { ble residue } \\
(\mathrm{wt} \%)\end{array}$ & $\begin{array}{l}\text { Yield THF-insolu- } \\
\text { ble residue } \\
(\mathrm{wt} \%)\end{array}$ & $\begin{array}{l}\text { Total yield } \\
(\text { wt\% })\end{array}$ \\
\hline 1 & 340 & $1: 40^{\mathrm{a}}$ & 12.8 & 64.23 & 20.97 & 98 \\
2 & 340 & $1: 30^{\mathrm{b}}$ & 15 & 51.09 & 31.25 & 97.3 \\
3 & 340 & $1: 20^{\mathrm{c}}$ & 23.1 & 33.51 & 40.29 & 96.9 \\
4 & 340 & $1: 10^{\mathrm{d}}$ & 9.2 & 13 & 73 & 95.2 \\
\hline
\end{tabular}

All experiments were performed at $850 \mathrm{rpm}$ stirring speed

a $4 \mathrm{~L}$ autoclave conditions: $40 \mathrm{~g}$ of lignin, $20 \mathrm{~g}$ of catalyst and $1600 \mathrm{~mL}$ of solvent

b4 L autoclave conditions: $53 \mathrm{~g}$ of lignin, $26 \mathrm{~g}$ of catalyst and $1600 \mathrm{~mL}$ of solvent

${ }^{c} 4 \mathrm{~L}$ autoclave conditions: $80 \mathrm{~g}$ of lignin, $40 \mathrm{~g}$ of catalyst and $1600 \mathrm{~mL}$ of solvent

d $4 \mathrm{~L}$ autoclave conditions: $160 \mathrm{~g}$ of lignin, $80 \mathrm{~g}$ of catalyst and $1600 \mathrm{~mL}$ of solvent 
higher lignin loadings and only if they result in high monomer production, lead to a higher ratio (g/g) of monomers/ total mass flow. This important CAPEX parameter, practically means that the mass of produced monomers (main lignin oil value driver) should be as high as possible compared to the total mass flow in the system, which is an indicator for big sizes of process equipment (e.g. catalytic reactor, distillation columns for solvent recovery, mixers etc.). Next to this, the second most crucial indicator is the ratio (g/g) produced monomers/ethanol losses. This ratio should be relatively high and is low OPEX driver, as it practically defines the $\mathrm{g}$ of monomers produced per $\mathrm{g}$ of ethanol lost in the process. By moderately increasing the lignin loading this ratio is also increasing, but the already obtained relative high monomer yields (Table 4, entry 3 ) is not able to compensate for the big loss of ethanol.

Next to these and in order to investigate the lower catalyst activity for the high lignin loading (Table 4 , entry 4), we followed a work-up procedure that was reported earlier by our group [3]. We performed a complete mass balance analysis for five critical temperature points, by distinguishing smaller, tetrahydrofuran (THF)-soluble and larger (THF-insoluble) lignin fragments. The THF-soluble residue contains lignin fragments with a lower molecular weight than the original lignin. The THF-insoluble lignin residue is a fraction that is strongly adsorbed on the solid catalyst and therefore cannot be dissolved in THF. We monitored the effect of high lignin loading in the $4 \mathrm{~L}$ batch autoclave until $6 \mathrm{~h}$ reaction time. Heating and pressurizing a $4 \mathrm{~L}$ reactor to the desired setpoint (temperature, pressure) is a long process. Figure 4 shows the operating window for the Entry 12 in Table 4. It is showed that almost $2 \mathrm{~h}$ are required until the autoclave reaches the desired process conditions. The results of the mass balances are depicted in Table 6.

In order to explain the low catalyst performance for the case of $1: 10 \mathrm{w} / \mathrm{v}$ lignin: ethanol ratio, we determined the THF-soluble and THF-insoluble fractions of the lignin residues, separately for five temperature points (Table 6). After the first $35 \mathrm{~min}$, both fractions were almost equally distributed. The THF-insoluble lignin residue on the catalyst surface was the dominant solid fraction at $250^{\circ} \mathrm{C}$. This fraction remained dominant at moderate temperatures of $300-340{ }^{\circ} \mathrm{C}$ after $4 \mathrm{~h}$ reaction time, reaching $73 \mathrm{wt} \%$. We performed energy dispersive X-ray spectroscopy and elemental mapping on the THF-insoluble residue (Table 6, entry 4) which includes the catalyst. From the SEM images (Fig. 5) we observed the formation of agglomerates between the catalyst and THF-insoluble lignin fragments. EDX elemental analysis (Fig. 5) showed a $10 \mathrm{wt} \%$ carbon deposition on the catalyst surface, indicating that the mixed pure nature of the $\mathrm{Cu}-\mathrm{Mg}-\mathrm{Al}$ components in the proper ratio is probably lost.

Based on the EDX results, the $\mathrm{Cu} / \mathrm{Al}$ weight ratio was significantly decreased from 2.55 in the fresh catalyst to 0.55 in

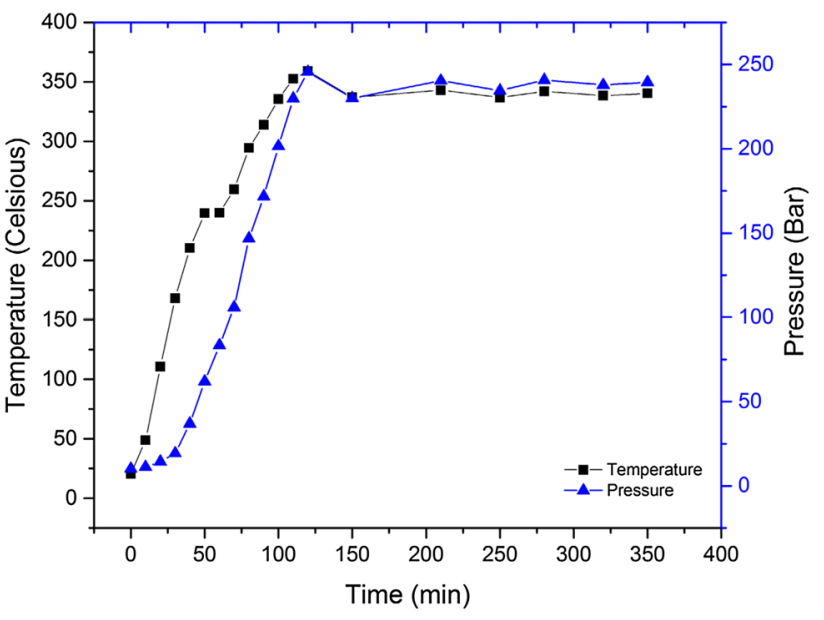

Fig. 4 Temperature and pressure operating window of $4 \mathrm{~L}$ reactor following reaction at $340{ }^{\circ} \mathrm{C}$, for $4 \mathrm{~h}$ and lignin: ethanol ratio $1: 10 \mathrm{w} / \mathrm{v}$ (Table 4, entry 4)

the spent catalyst. The $\mathrm{Mg} / \mathrm{Al}$ weight ratio decreased slightly from 3.53 to 3.16 and the total $(\mathrm{Cu}+\mathrm{Mg}) / \mathrm{Al}$ weight ratio decreased from 6.08 to 3.72. Given the fact that the biggest decrease is given by the $\mathrm{Cu} / \mathrm{Al}$ ratio ( $78 \%$ decrease), this is a first sign that coke formation is favored on the $\mathrm{Cu}$ sites rather than $\mathrm{Mg}$, thus deactivating the catalyst. Huang et al. [9] extensively studied the effect of $\mathrm{Cu}-\mathrm{Mg}-\mathrm{Al}$ mixed oxide catalysts in lignin depolymerization in supercritical ethanol. The combination of $\mathrm{Cu}$ and basic sites, as well as Lewis acid sites, is crucial for obtaining high monomer yield and low rates of repolymerized lignin fragments during the reaction. The combination of basic sites with $\mathrm{Cu}$ facilitates the dehydrogenation of ethanol, producing hydrogen needed for the hydrogenolysis reactions, which leads to a high fraction of deoxygenated monomer products.

Catalyst recyclability is an important aspect in the realization of industrial processes. In a previous work of our lab scale process $[9,11]$ we determined the reusability of the spent catalyst employed at temperature of $380^{\circ} \mathrm{C}$ for $8 \mathrm{~h}$ and 1:40 w/v lignin: ethanol ratio. The monomer yield was the highest we have reported (60 wt \%) and $10 \mathrm{wt} \%$ of char was present due to carbonization reactions. The solid residue of the reaction, which included the catalyst, was subjected to a regeneration procedure (calcination at $500{ }^{\circ} \mathrm{C}$ for $6 \mathrm{~h}$ ) and then employed for another reaction. The performance of the recovered catalyst was significantly lower than the fresh one. The lignin monomers yield that was reported was $39 \mathrm{wt} \%$ after the first cycle and $16 \mathrm{wt} \%$ after the second recycle. These findings pointed out that the catalyst cannot be completely regenerated by calcination at $500{ }^{\circ} \mathrm{C}$. The loss of basic sites due to hydrolysis of $\mathrm{MgO}$ and loss of surface area due to spinel oxide formation of the $\mathrm{Cu}$ and $\mathrm{Al}$ components were already reported and identified as the main causes for the lower activity of the regenerated catalyst. 
Table 6 Mass balances of the lignin residues obtained for reactions at $200-340{ }^{\circ} \mathrm{C}$ and lignin: ethanol ratio $1: 10 \mathrm{w} / \mathrm{v}$, over the $\mathrm{CuMgAl}$ mixed oxide catalyst, in the $4 \mathrm{~L}$ autoclave reactor

\begin{tabular}{llllllll}
\hline Entry & $\begin{array}{l}\text { Temp. } \\
\left({ }^{\circ} \mathrm{C}\right)\end{array}$ & $\begin{array}{l}\text { Time } \\
(\mathrm{min})\end{array}$ & $\begin{array}{l}\text { Lignin: } \\
\text { EtOH ratio }^{\mathrm{b}} \\
(\mathrm{w} / \mathrm{v})\end{array}$ & $\begin{array}{l}\text { Yield THF- } \\
\text { soluble residue } \\
(\mathrm{wt} \%)\end{array}$ & $\begin{array}{l}\text { Yield } \\
\text { THF-insolu- } \\
\text { ble residue } \\
(\mathrm{wt} \%)\end{array}$ & $\begin{array}{l}\text { Yield lignin } \\
\text { monomers } \\
(\mathrm{wt} \%)\end{array}$ & $\begin{array}{l}\text { Total Yield } \\
(\mathrm{wt} \%)\end{array}$ \\
\hline 1 & 200 & $35^{\mathrm{a}}$ & $1: 10$ & 52 & 46 & 0.4 & 98.4 \\
2 & 250 & $60^{\mathrm{a}}$ & $1: 10$ & 26 & 73 & 0.5 & 99.5 \\
3 & 300 & $80^{\mathrm{a}}$ & $1: 10$ & 23 & 74 & 2 & 98 \\
4 & 340 & $125(0 \mathrm{~h})^{\mathrm{a}}$ & $1: 10$ & 20 & 73 & 4 & 97 \\
5 & 340 & $365(4 \mathrm{~h})$ & $1: 10$ & 13 & 73 & 9.2 & 95.2 \\
\hline
\end{tabular}

${ }^{\mathrm{a}}$ Time needed to reach the temperature set point of each entry

${ }^{\mathrm{b}} 4 \mathrm{~L}$ autoclave conditions: $160 \mathrm{~g}$ of lignin, $80 \mathrm{~g}$ of catalyst, $1600 \mathrm{~mL}$ of solvent and $850 \mathrm{rpm}$ stirring speed

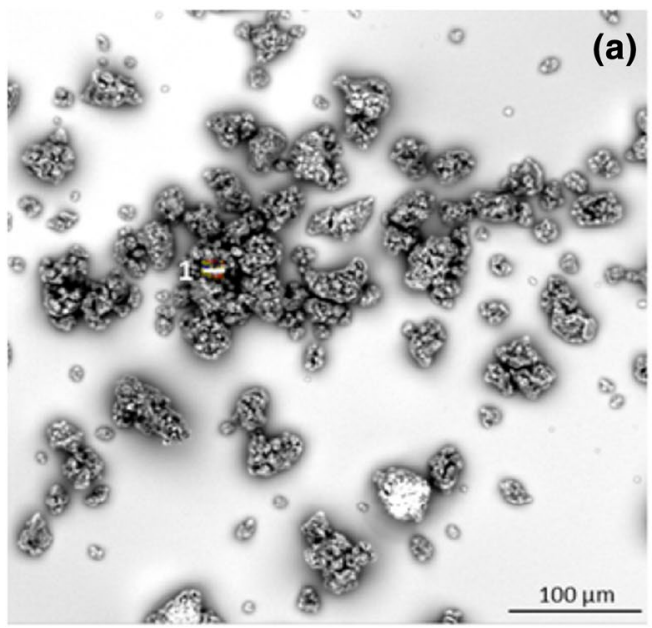

(a)
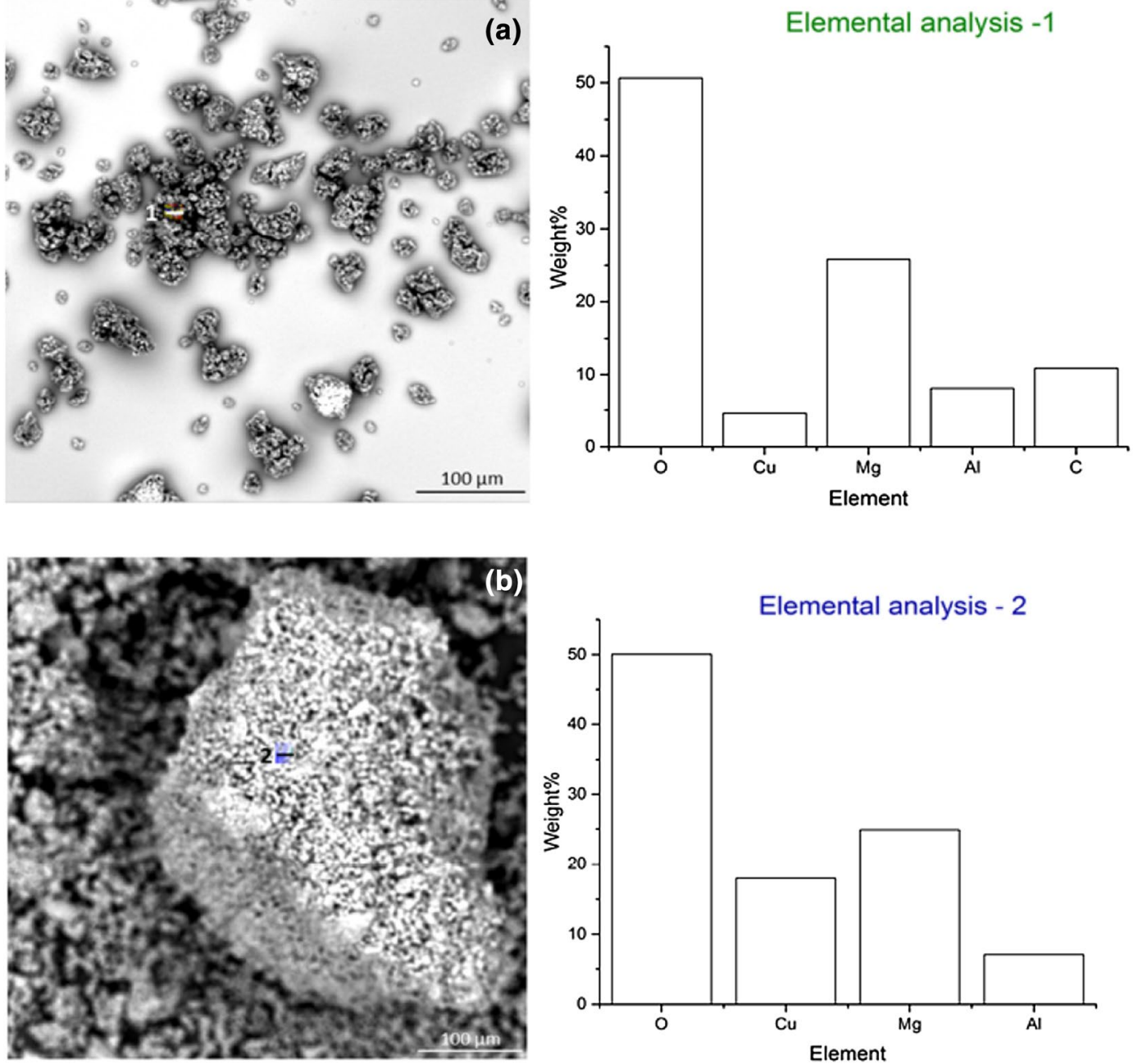

Fig. 5 SEM picture a showing the formation of agglomerates between the $\mathrm{Cu}-\mathrm{Mg}-\mathrm{Al}$ mixed oxide catalyst with the THF-insoluble large lignin fragments, obtained after reaction at $340{ }^{\circ} \mathrm{C}, 0 \mathrm{~h}$ and $1: 10$ w/v lignin: ethanol ratio. Below, the SEM picture b represents the

The solubility of lignin in ethanol occurs at low temperatures (up to $200{ }^{\circ} \mathrm{C}$ ) and is decreasing when higher lignin loadings are applied (Table 6, entry 1 ). As a result, the undissolved amount of lignin is capturing any available fresh catalyst. Elemental analysis 1 and 2 refer to the regions highlighted in the image $\mathbf{a}$ and $\mathbf{b}$ respectively. The percentage weights of each element of the spectra are reported in the related histograms

surface in the reactor including the catalyst surface. When the reaction temperature is increasing, these lignin fragments are strongly adsorbed on the catalyst surface, creating agglomerates. These findings indicate that the fouling of the 
$\mathrm{Cu}_{20} \mathrm{MgAl}$ (4) starts already from $0 \mathrm{~h}$ and the low monomer yield after $4 \mathrm{~h}$, is due to carbon deposition on the catalyst surface, an effect that is strongly related with the solubility limits of lignin in ethanol.

Catalyst fouling remains crucial performance criterion for commercialization and is strongly related with the lignin: ethanol ratio, as described in the previous paragraphs. It is therefore substantially connected with the required CAPEX and OPEX in the process. We showed that by increasing the lignin loading, we can increase the ratio $(\mathrm{g} / \mathrm{g}$ ) mass monomers/total feed and the ratio $(\mathrm{g} / \mathrm{g})$ mass monomers/ethanol losses. But if we continue more, this comes at the expenses of the catalyst fouling, which drops dramatically the monomer yield (Table 4). In this case, additional expenditure is required for the catalyst regeneration.

\section{Conclusions}

We scaled-up from lab $(50-100 \mathrm{~mL})$ to bench $(4000 \mathrm{~mL})$ a catalytic depolymerization process for sulphur-free technical lignin in supercritical ethanol. This process works with a $\mathrm{Cu}$-doped MgAl mixed oxide catalyst. Lab scale results were reported earlier by our group in [3, 9-11]. This paper investigated the impact of scaling at equal process conditions, as well as the influence of higher lignin loadings than previously reported, on, amongst other parameters, monomer yield, solvent losses and catalyst fouling, of all which being important performance parameters for industrial operation.

- At bench scale with diluted lignin: ethanol ratios similar to those applied at lab scale, $11 \mathrm{wt} \%$ of monomer yield was obtained at $340{ }^{\circ} \mathrm{C}$ for $4 \mathrm{~h}$. The yield was decreased by factor 3 due to geometric dissimilarities between the two reactors. Geometric inconsistency in the dimensions is responsible for the creation of stagnant zones filled with unconverted lignin feed. We were able to overcome these issues, by applying higher stirring speeds and increasing the lignin loading in the reactor. Up to $23 \mathrm{wt} \%$ monomer yield could be obtained, at $340{ }^{\circ} \mathrm{C}, 4 \mathrm{~h}$ reaction time and 1:20 w/v lignin: ethanol ratio.

- Except for the geometric similarity that has to be applied during any scale-up process towards the successful implementation of the technology, we argue that the main CAPEX and OPEX drivers for the process are the lignin: solvent ratio, solvent losses, and catalyst fouling.

- Low lignin: solvent ratios and diluted feeds will require massive flows of solvents which are translated to greater equipment size (e.g., catalytic reactors, distillation columns for solvent recovery, mixers). The monomer/feed ratio should be relatively high to ensure affordable CAPEX for commercialization. It was shown that this ratio increased with higher lignin loadings.
- We can lower the CAPEX and OPEX indicators by moderately increasing the lignin loadings, but in extreme cases, the additional expenses of catalyst fouling arise. It was found that in 1:10 w/v lignin: ethanol ratio the catalyst activity drops significantly.

- The most important OPEX performance criterion is arguably the ethanol loss in the process. It was found that, although we optimized to lignin loading in terms of higher selectivity to monomers, the monomer yield was extremely low compared to the ethanol losses and not sufficient to replenish the loss of value $(0.031 \mathrm{~g}$ of monomers produced/1 $\mathrm{g}$ of ethanol lost). Ethanol losses can be considered one of the main lignin monomer cost drivers, thus their minimization is crucial for technoeconomic viability.

- Our lignin oil value driver to optimize monomer yield, in terms of higher lignin loadings, resulted in catalyst fouling, which is also an important process performance parameter. Deposition of heavy and poorly soluble lignin fragments onto catalyst surface lowers the catalytic activity; a fact that requires extra CAPEX/ OPEX for catalyst regeneration. This points out that new concepts on process design should be implemented in order to avoid contact of the fouling agents with the required heterogeneous catalysts.

- After completing this early stage techno-economic evaluation, by using the three relative CAPEX/OPEX indicators (Table 1), we believe that it would be very cost intensive to implement this technology on a lignin production site (e.g. $2 \mathrm{G}$ cellulosic ethanol plants). Although we were able to replenish the lignin monomer yield, by increasing the lignin loading, the ethanol losses in all cases are too pronounced that commercialization seems very challenging. Solvent losses are the main lignin oil cost driver, making this promising technology nonviable. Alternatively, we observed that ethanol conversion remains below $5 \mathrm{wt} \%$ (Table 2, entry 1a) when the catalyst is not involved and additionally the THF-soluble lignin fragments were $52 \mathrm{wt} \%$ at $200{ }^{\circ} \mathrm{C}$ and short residence times (Table 6, entry 1). Strategically, this means that on-site we can convert without a catalyst a large amount of lignin into a crude lignin oil (mainly composed of large lignin fragments/oligomers) via a thermal solvolysis step. Then the lignin oil can be transferred in centralized biorefineries and can be further upgraded catalytically. In a centralized concept, economy of scale allows further downstream processing in order to recover and valorise most of the ethanol products from this process. By this, we could minimize the ethanol losses on-site, and ensure that the undissolved lignin residue will not be present in the intermediate lignin oil, thus cannot poison the catalyst in the second step. 
- Finally, extended research and optimization protocols should be further implemented, not only in this technology but in most of the cited lab-scale lignin processes, in order to evaluate them and successfully transfer them into higher technology readiness levels.

Acknowledgements This work was performed under the framework of Chemelot InSciTe and is supported by financial contributions from the European Interreg V Flanders, the European Regional Development Fund (ERDF) within the framework of OP-Zuid, the province of Brabant and Limburg and the Dutch Ministry of Economy.

Open Access This article is distributed under the terms of the Creative Commons Attribution 4.0 International License (http://creativeco mmons.org/licenses/by/4.0/), which permits unrestricted use, distribution, and reproduction in any medium, provided you give appropriate credit to the original author(s) and the source, provide a link to the Creative Commons license, and indicate if changes were made.

\section{References}

1. Rinaldi $\mathrm{R}$ et al (2016) Paving the way for lignin valorisation: recent advances in bioengineering, biorefining and catalysis. Angewandte Chemie 55(29):8164-8215

2. Bartlett RA (1995) Troubled waters: Champion International and the Pigeon River controversy, 1st edn. University of Tennessee Press, Knoxville

3. Huang X, Korányi TI, Boot MD, Hensen EJM (2014) Catalytic depolymerization of lignin in supercritical ethanol. ChemSusChem 7(8):2276-2288

4. Nielsen JB, Jensen AD, Nielsen J (2016) Valorization of lignin from biorefineries for fuels and chemicals. Technical University of Denmark (DTU), Kongens Lyngby

5. Azadi P, Inderwildi OR, Farnood R, King DA (2013) Liquid fuels, hydrogen and chemicals from lignin: a critical review. Renew Sustain Energy Rev 21:506-523

6. Barta K, Matson TD, Fettig ML, Scott SL, Iretskii AV, Ford PC (2010) Catalytic disassembly of an organosolv lignin via hydrogen transfer from supercritical methanol. Green Chem 12(9):1640

7. Matson TD, Barta K, Iretskii AV, Ford PC (2011) One-pot catalytic conversion of cellulose and of woody biomass solids to liquid fuels. J Am Chem Soc 133(35):14090-14097

8. Song Q et al (2013) Lignin depolymerization (LDP) in alcohol over nickel-based catalysts via a fragmentation-hydrogenolysis process. Energy Environ Sci 6(3):994

9. Huang X, Atay C, Korányi TI, Boot MD, Hensen EJM (2015) Role of $\mathrm{Cu}-\mathrm{Mg}-\mathrm{Al}$ mixed oxide catalysts in lignin depolymerization in supercritical ethanol. ACS Catal 5(12):7359-7370
10. Huang X, Korányi TI, Boot MD, Hensen EJM (2015) Ethanol as capping agent and formaldehyde scavenger for efficient depolymerization of lignin to aromatics. Green Chem 17(11):4941-4950

11. Huang X et al (2017) Catalytic depolymerization of lignin and woody biomass in supercritical ethanol: influence of reaction temperature and feedstock. ACS Sustain Chem Eng 5:10864-10874

12. Güvenatam B, Heeres EHJ, Pidko EA, Hensen EJM (2016) Lewis acid-catalyzed depolymerization of soda lignin in supercritical ethanol/water mixtures. Catal Today 269:9-20

13. Jongerius AL, Bruijnincx PCA, Weckhuysen BM (2013) Liquidphase reforming and hydrodeoxygenation as a two-step route to aromatics from lignin. Green Chem 15(11):3049

14. Deepa AK, Dhepe PL (2015) Lignin depolymerization into aromatic monomers over solid acid catalysts. ACS Catal 5(1):365-379

15. Wang X, Rinaldi R (2012) Solvent effects on the hydrogenolysis of diphenyl ether with raney nickel and their implications for the conversion of lignin. ChemSusChem 5(8):1455-1466

16. Deuss PJ et al (2016) Metal triflates for the production of aromatics from lignin. ChemSusChem 9(20):2974-2981

17. Deuss PJ, Scott M, Tran F, Westwood NJ, De Vries JG, Barta K (2015) Aromatic monomers by in situ conversion of reactive intermediates in the acid-catalyzed depolymerization of lignin. J Am Chem Soc 137(23):7456-7467

18. Lange JP (2015) Renewable feedstocks: the problem of catalyst deactivation and its mitigation. Angew Chem 54(45):13187-13197

19. Nielsen JB, Jensen A, Schandel CB, Felby C, Jensen AD (2017) Solvent consumption in non-catalytic alcohol solvolysis of biorefinery lignin. Sustain Energy Fuels 1(9):2006-2015

20. Harmsen J (2013) Industrial process scale-up: a practical guide from idea to commercial implementation. Elsevier, New York, pp 1-6

21. Edwards D (2012) Scaling up step by step. Biofuels Intl $9(6): 44-46$

22. Moore FT (1959) Economies of Scale: some statistical evidence. vol 73, no. 2, Oxford University Press, Oxford, pp 232-245, http:// www.jstor.org/stable/1883722

23. Gallagher PW, Brubaker H, Shapouri H (2005) Plant size: capital cost relationships in the dry mill ethanol industry. Biomass Bioenerg 28(6):565-571

24. Zlokarnik M (1991) Dimensional analysis and Scale-up in chemical engineering, vol 1. Springer, New York

25. Harmsen $\mathbf{J}$ (2013) Industrial process scale-up: a practical guide from idea to commercial implementation, chap 6, pp 55-58

26. Harmsen J (2013) Industrial process scale-up: a practical guide from idea to commercial implementation, chap 4, pp 45-51

27. Harmsen J (2013) Industrial process scale-up: a practical guide from idea to commercial implementation, chap 7, pp 59-71

28. Hayes RE (2012) Introduction to chemical reactor analysis, 2 edn. CRC Press, Boca Raton

29. Green DW, Perry RH (1934) Perry's chemical engineers' handbook, 8th edn. McGraw-Hill, New York 